\title{
Usage of WhatsApp and voice calls (phone call): Preference of polytechnic students in Ghana
}

\author{
Yeboah Solomon Tawiah ${ }^{1}$, Horsu Emmanuel Nondzor ${ }^{1}$, Abdulai Alhaji ${ }^{2}$ \\ ${ }^{1}$ School of Business and Management Studies, Department of Marketing, Cape Coast Polytechnic, Cape Coast, Ghana \\ ${ }^{2}$ School of Applied Sciences and Arts, Department of Liberal Studies, Cape Coast Polytechnic, Cape Coast, Ghana
}

\section{Email address:}

soloty2002@gmail.com (S. T. Yeboah),rtchorsu8@gmail.com (H. E. Nondzor), aspicious@yahoo.co.uk (A. Alhaji)

\section{To cite this article:}

Yeboah Solomon Tawiah, Horsu Emmanuel Nondzor, Abdulai Alhaji. Usage of WhatsApp and Voice Calls (Phone Call): Preference of Polytechnic Students in Ghana. Science Journal of Business and Management. Vol. 2, No. 4, 2014, pp. 103-108.

doi: 10.11648/j.sjbm.20140204.11

\begin{abstract}
With the surge of social network and more improving technological messaging functionalities, Polytechnic students in Ghana are more likely to rely on WhatsApp application for their day-to-day communications than mobile voice calls (phone calls). Cost efficiency, effective, quick and easier mode of communication, confidential, and convenient usage are some of the major factors which might influence their decision. However, not much is known empirically of students' preference of voice calls and WhatsApp applications. Thus, the objective of the study was to empirically investigate students' preference of WhatsApp and voice calls in Ghana. A cross sectional approach was used from January to June, 2014. Both primary data and secondary data were used. A structured questionnaire was employed to collect data from a sample of 600 students in three polytechnic institutions in Ghana. Descriptive statistics- tables, pie charts and percentages were used to present the data. The empirical evidence suggests that students' attention is switching to WhatsApp application as their most preferred mode of their day-to-day communications than it is to mobile voice calls. But it was observed that the kind of the situation and circumstances relating to the communication determines what choice they make. Most prefer using phone calls for situations where they need to be more expressive and effective, as well as in their formal communications. However, in communications involving peers and mates such as to say hi, sharing of academic materials etc., WhatsApp emerged as a preferred choice. It was found that, although WhatsApp is making in-roads per students' preference, voice calls still remain more important to them as they rely on it at certain situations and circumstances for their communication.
\end{abstract}

Keywords: Social Network, Social Media, WhatsApp, Voice Calls, Phone Calls, Students, Preference

\section{Introduction}

Today's world is predominantly technological driven which has brought about diverse innovation. The complexity of these technologies requires users to abreast themselves with the ever-increasing changes in these technologies. Therefore service providers have to responsively embrace these changes to meet the demands of their consumers. One of such innovations is the upsurge of social network technology.

The Social media and social network tools especially WhatsApp Messenger, Facebook, and Viber etc., have become dominant factor in today's digital world. These social media and network are affecting how users communicate and businesses operate [1]. Research $[1 ; 2 ; 3]$ has shown that, companies are exploiting these social media and networks to maintain customers' loyalty, participation, and their opinions for market research. There is also a growing body of international evidence demonstrating the positive impact of digital messaging technologies and this has had positive impact on teen and the youth $[1 ; 4 ; 5]$ including their preference of mobile voice calls.

Its seeming benefits such as - the ability to create, share, adapt and reuse content engage in digital dialogue and collaborate, have peer-to-peer contact, social interaction with other users, its discoverability, and continuous accessibility have attracted greater number of digital communication users using the platform $[3 ; 7 ; 8 ; 9]$.

Today, just a click of a button gives consumers an 
opportunity to communicate virtually freely via several messaging platforms including WhatsApp messenger to share their experiences with other users across the globe. WhatsApp messenger offers free texting and attempt to shift mobile consumers' preference from the traditional short messages services (SMS). Texting in general have been found to be dominating people's interaction and has affected mobile voice call revenue $[4 ; 6 ; 7]$. For instance in the United Kingdom (UK), 58 and $90 \%$ adults and teenagers respectively have been found to send out messages at least once a day to communicate with family and friends with the total number of texts sent in the UK in 2011 around 150 billion [4]. Ofcom [4] also stated that the amount of calls from landlines and mobile phones fell in the same year.

In Ghana, WhatsApp is seen as a cost buster, more convenient and an alternative to poor quality of voice service provided by the cellular networks companies [6]. The explosive interests of these messaging platforms and social networks or media across the globe, especially, among the youth calls for considerable interest of study into this area. In view of this, the research sought to find out the preference of polytechnic students on the usage of WhatsApp and mobile voice calls.

\section{Methods}

\subsection{Study Design, Area and Period}

A cross-sectional study was undertaken from January to June, 2014 among students of three polytechnic institutions in Ghana: Cape Coast Polytechnic (C'poly), Accra Polytechnic (Accra poly), and Takoradi Polytechnic (T'poly). Cape coast, Accra and Takoradi are regional capitals of Central Region, Greater Accra and Western Region respectively. The three institutions studied are the leading polytechnics among the ten existing polytechnics in Ghana. The academic units among the three institutions are not different from each other. The units consist of School of Business and Management Studies, School of Engineering, and School of Applied Sciences and Arts.

\subsection{Study Population, Sampling and Data Collection}

The study population consists of all level 100 to 300 HND mainstream students in Ghana. Students study under Access, Diploma in Business Studies and evening schools were not included in the study since they possess different characteristics from the HND students in terms of programme, time, and lifestyle.

The study population which is made up of polytechnic students in Ghana is extremely huge. As a result, the study sampled six hundred students from the population of study consisting of Cape Coast Polytechnic (C'poly), Accra Polytechnic (Accra poly), and Takoradi Polytechnic (T'poly) using pretested structured questionnaire. The study instrument was based on both primary and secondary data. The students were stratified into various educational levels and self-administered questionnaires distributed to them randomly. The data gathered were analysed using descriptive statistics and results presented in tables, percentages and bar charts.

\section{Results}

The section analyses the responses gathered from the students from the structured questionnaire. For the purposes of clarity and easier interpretation, the responses were first presented in bar charts, tables and their interpretation and analyses followed thereafter.

\subsection{Age and Sex Distribution of Respondents}

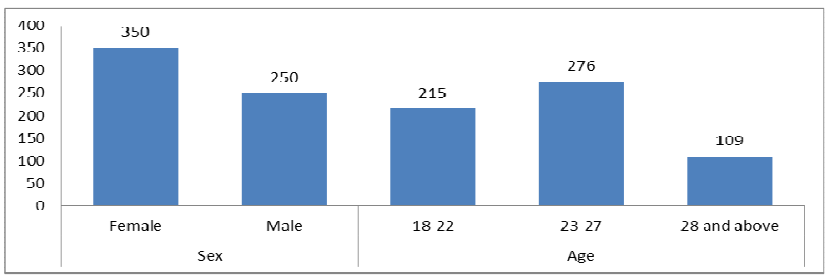

Source: Survey Data [2014]

Figure 1. Age and Sex Distribution of respondents

Figure 1 represents the number of students who were randomly selected across various campuses. Regarding the gender sampled, 350(58.3\%) represent female while $250(41.6 \%)$ represent male $-($ Female, $n=350$, and Male, $n=$ 250). The age distribution were made up of the following: $18-22(36 \%) ; 23-27$ (46\%); and, 28 and above representing $(18 \%)$.

\subsection{WhatsApp Familiarity, Usage and Reasons for not Using}

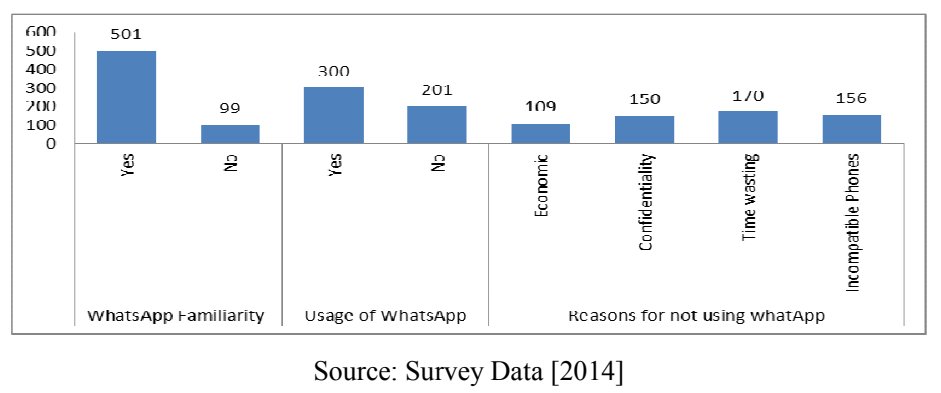

Figure 2. WhatsApp familiarity, usage and reasons for not using 
WhatsApp has gained familiarity with students. A total of $501(83.5 \%)$ students expressed their faimiliarity with WhatsApp application. Also a total of $300(60 \%)$ students indicated they use the application. Besides, 99 students (16.5\%) out of the 600 specified they are not familiar with WhatsApp messenger. Out of the 501 students (i.e. 83.5\%) who are familiar with the application, 201 (ie 40\%) of them indicated they are not using the application. The students were asked to indicate the reasons why they are not using the application: Economic (109 responded); Confidentiality (150 responded); Time wasting (170 responded); and incompatible phones (156 responded) were the various responses. The students had the options to choose more than one answer.

\subsection{Familiarity with Voice Call and Reasons for not Using it}

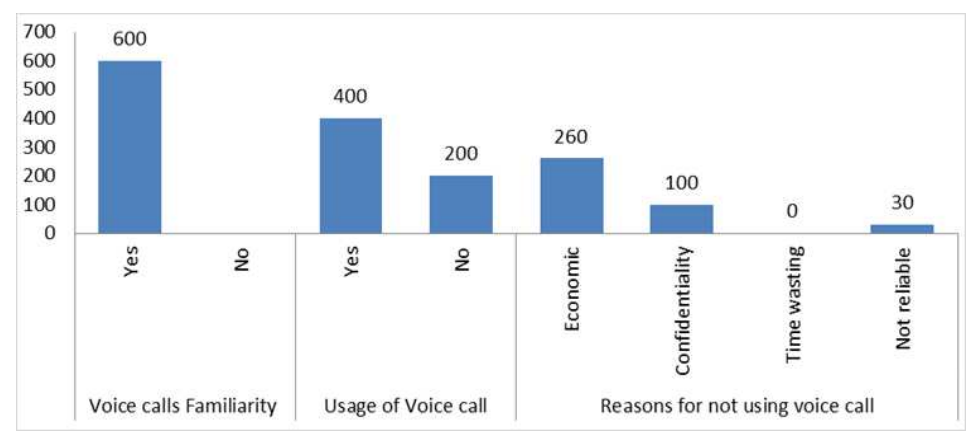

Source: Survey Data [2014]

Figure 4. Familiarity with voice call and reasons for not using it

Undisputably, voice call is the most familiar among the students. Every student (100\%) was familiar with voice call. However, only a total of 400 students $(67 \%)$ indicated their usage of voice call. A total of 200 students (33\%) said they are not using voice call. Asked to indicate the reasons for not using voice call from four restricted answers where

\subsection{Future Usage of WhatsApp Messaging}

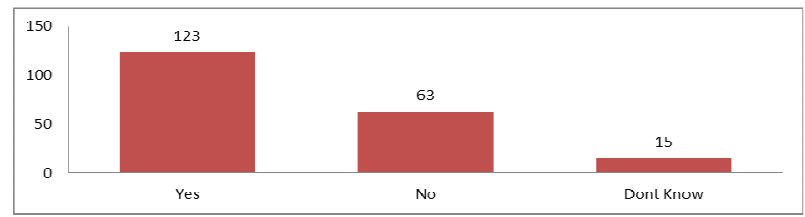

Source: Survey Data [2014]

Figure 3. Future usage of whatsApp messaging

The students were asked to indicate their future usage. A total of $123(61 \%)$ students indicated their willingness to use the applicaiton, whiles $63(31 \%)$ students responded to the 'No' answer (not willing to use in future). Also 15 students (equalling 7\%) said they are indifferent to the usage. they had the option to choose more than one answer. Distribution of their answers include the following: Economic (260), condientiality (100), unrelaibility (30) and time wasting $(0)$.

\subsection{Type of Media Used Most Often for Common Comunication}

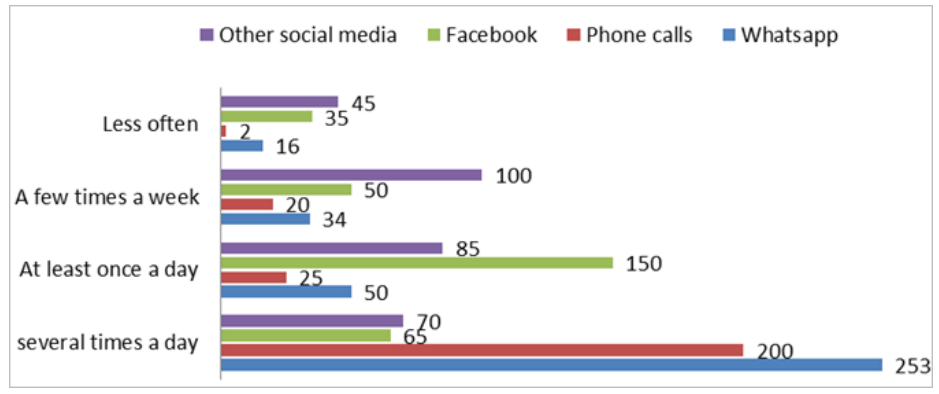

Source: Survey Data [2014]

Figure 5. Type of media used most often for common comunication

A comparison was made among the types of media used most often by the students in their communication. The students had the option to choose more than one answers. Over all 253 students use WhatsApp several times a day more than voice call (200), Facebook (65), and any other social media (70). The students however, visit Facebook at least once a day more than all other networks and they spend more time a few times a week in other social media. 


\subsection{Daily and Situational Usage of WhatsApp and Phone Calls}

Table 1. Comparison between student's preference of daily usage and frequency of WhatsApp and phone calls

\begin{tabular}{|c|c|c|c|c|c|c|}
\hline \multirow{3}{*}{ Contacts } & \multicolumn{6}{|c|}{ Daily Frequency } \\
\hline & \multicolumn{2}{|c|}{ Thrice or more } & \multicolumn{2}{|l|}{ Twice } & \multicolumn{2}{|l|}{ Once } \\
\hline & WhatsApp & Voice call & WhatsApp & Voice call & WhatsApp & Voice call \\
\hline Parents/Guardians & 20 & 75 & 30 & 70 & 10 & 40 \\
\hline Lecturers & 100 & 30 & 50 & 25 & 30 & 32 \\
\hline Friends & 265 & 54 & 5 & 3 & 10 & 7 \\
\hline Fiancée/Spouse & 260 & 45 & 10 & 20 & 28 & 50 \\
\hline Religious Leaders & 45 & 70 & 36 & 35 & 25 & 65 \\
\hline Colleagues & 45 & 12 & 20 & 50 & 57 & 26 \\
\hline
\end{tabular}

Source: Survey Data [2014]

Students were asked to indicate their daily preference of media and frequency to parents/guardians, lecturers, friends, fiancée/spouse, religious leaders and colleagues. The results indicated that students prefer contacting their parents and guardians thrice or more times by voice calls than WhatsApp (20 students for WhatsApp with 75 by voice calls). They also prefer using WhatsApp to contact lecturers (100 students) more than voice calls (just 30 students) Besides, a total of 265 students use WhatsApp as against 54 using voice calls to contact friends. A total of 260 students use WhatsApp thrice or more times in a day to contact fiancée/spouse more than voice call which has a total of 45 students to contact same. Religious leaders and colleagues attracted similar number of 45 students but 70 prefer voice calls and 12 represent colleagues respectively.

\subsection{Situational Usage of WhatsApp and Phone Calls}

Asked to indicate in the situations in Table 2 where they would prefer WhatsApp or phone calls as a means of communication. WhatsApp prevailed most. The students preferred mode of communication in the situations given above except for the private exchanges of information where phone calls registered $207(69 \%)$ as against 93 (31\%) for WhatsApp. But in other situations in which phone calls are used rather than WhatsApp, 159 prefer using phone calls in some situations and 141 preferring WhatsApp. Some of the responses recorded by respondents in situations where they would use phone calls include the following: lengthy formal discussions, reporting complaints and incidents, tracing a missing examination grades from academic office, chatting with parents, reporting to crime officers and contacting their bankers, etc. However, among some of the lists specified by respondents for WhatsApp included the following: alerting friends of issues relating to coursework, ending their relationships with fiancées, gossip about someone including course mates and lecturers, sending images of interest, and reminding friends of appointments etc.

Table 2. Situational Usage of WhatsApp and Phone calls

\begin{tabular}{lll}
\hline Situation & WhatsApp & Phone calls \\
\hline To just say hi and chat & 245 & 55 \\
Inform about your location/someone & 156 & 144 \\
whereabouts & 200 & 100 \\
To link up or meeting with someone & 287 & 13 \\
Issues related to coursework & 243 & 57 \\
To chat on both vital and trivial issues & 93 & 207 \\
For private exchanges of information & 170 & 130 \\
For association/club meetings on online & 141 & 159 \\
Other specify & & \\
\hline
\end{tabular}

Source: Survey Data [2014]

\subsection{Expenditure on Voice Calls before and after Subscribing to WhatsApp}

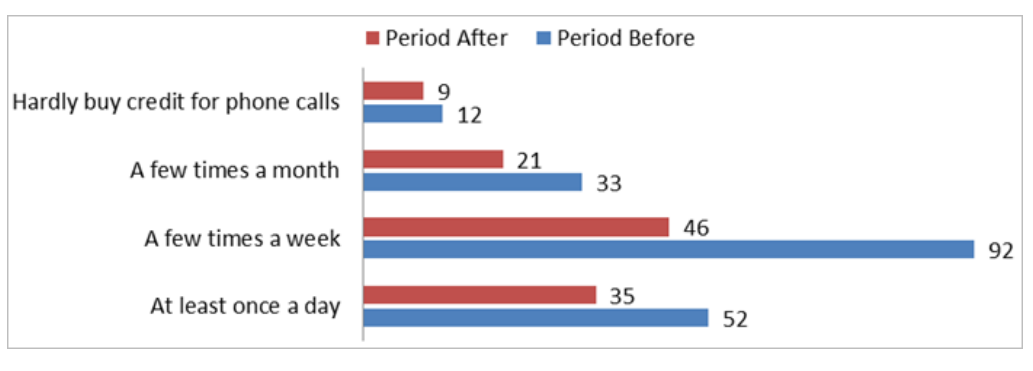

Source: Survey Data [2014]

Figure 6. Expenditure on voice calls before and after subscribing to WhatsApp

Asked whether their subscription to WhatsApp has impacted their expenditure on voice calls, the following results were obtained from the students. For students who hardly buy credit after subscription to WhatsApp, the number decreased from $12(4 \%)$ before subscription to $9(3 \%)$ after subscription. Students spending a few times in a month dropped from 33 (11\%) before subscription to 21 (7\%) after subscription. Students spending on voice calls 
in a few times a week dropped from 92(31\%) before subscription to 46 (15\%) after subscription. Lastly, students spending in at least once a day dropped from $52(17 \%)$ before subscription to 35 (12\%) after subscription.

\subsection{Perceptions on WhatsApp and Voice Calls}

Table 3. Perceptions on whatsapp and voice calls

\begin{tabular}{|c|c|c|c|c|c|}
\hline \multirow[b]{2}{*}{ Statements } & \multicolumn{5}{|l|}{ Response } \\
\hline & Strongly agree & Agree & $\begin{array}{l}\text { Neither agree nor } \\
\text { Disagree }\end{array}$ & disagree & $\begin{array}{l}\text { Strongly } \\
\text { Disagree }\end{array}$ \\
\hline $\begin{array}{l}\text { WhatsApp offers easier and convenience communication } \\
\text { than phone calls }\end{array}$ & 120 & 130 & 2 & 45 & 3 \\
\hline WhatsApp offers money safer than phone calls & 265 & 20 & 0 & 15 & 0 \\
\hline WhatsApp is more difficult to use than phone calls & 3 & 53 & 0 & 47 & 197 \\
\hline WhatsApp is more reliable and effective than phone calls & 79 & 70 & 65 & 49 & 37 \\
\hline WhatsApp protects personal information than phone calls & 50 & 67 & 20 & 80 & 83 \\
\hline $\begin{array}{l}\text { WhatsApp will influence my choice of a phone than just a } \\
\text { basic phone call }\end{array}$ & 110 & 80 & 25 & 77 & 8 \\
\hline WhatsApp has really affected my phone calls & 205 & 55 & 30 & 10 & 0 \\
\hline $\begin{array}{l}\text { Phone calls still remains most important mode of } \\
\text { communication choice }\end{array}$ & 211 & 40 & 3 & 12 & 34 \\
\hline $\begin{array}{l}\text { I depend on WhatsApp for most of my communication } \\
\text { than phone calls }\end{array}$ & 202 & 34 & 64 & 0 & 0 \\
\hline
\end{tabular}

Source: Survey Data [2014]

Students were asked to indicate level of agreement. On whether WhatsApp offers easier and convenient communication than voice call, 120 students (40\%) strongly agreed to the statement with 130 (43\%) agreeing to the statement. Similarly, just 2 students $(0.6 \%)$ were indifferent, (i.e. neither disagree nor agree) to the statement. Also 45 students (15\%) and 3 students (1\%) disagreed and strongly disagreed respectively. Besides, on whether WhatsApp offers money safer than voice call, the following responses were registered: 265 students (88\%) strongly agreed to the statement; 20 students (7\%) agreed; and 15 students $(5 \%)$ expressed disagreed. However, on whether WhatsApp protects personal information than phone calls 50 students $(17 \%)$ strongly agree, 67students (22\%) agree with 20 students $(7 \%)$ neither agree or disagree, however a total of 80 students $(27 \%)$ disagree, whilst 83 students (28\%) strongly disagreed with the statement. On whether WhatsApp has really affected their phone calls, a total of 205 students (68\%) strongly agree the application has affected their voice calls whereas 55 students (18\%) agreed to the statement. A total of 30 students $(10 \%)$ were indifferent to the same statement. Also 10 students $(3 \%)$ disagreed to same statement but none of them strongly disagreed. Moreover on whether phone call still remains important mode of communication, as many as 211 students $(70 \%)$ agreed to the statement. A total of 40 students $(13 \%)$ agreed with 3 students (1\%) agreeing to the same statement. Both disagree (12) and strongly disagree (34) responses registered a total of $15 \%$ of the students. Finally, a majority of 202 students (67\%) strongly agree to depend on WhatsApp for most of their communication than voice call with 34 students (11\%) agreeing to same statement. Similarly, 64 (21\%) students neither agree nor disagreed to the same statement but none of the students disagreed or strongly disagreed to the statement.

\subsection{Preference of WhatsApp and Voice Calls}

Students were asked to indicate their preference of WhatsApp and voice call. Overall, 276 students (92\%) indicated their preference of WhatsApp over voice call. However, 24 students $(8 \%)$ rather prefer voice calls to WhatsApp.

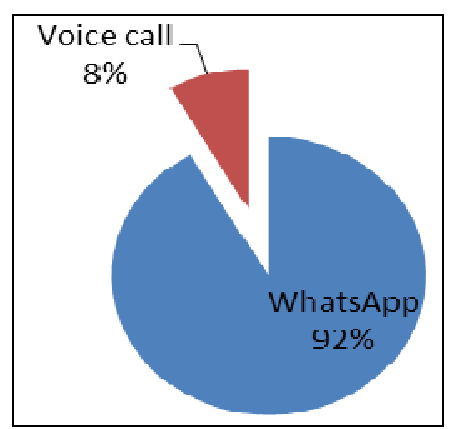

Figure 7. Preference of WhatsApp and Voice calls

\section{Discussion and Conclusion}

\subsection{Discussion}

Social media and networks are useful additions to the collections of technology-enhanced learning. Many reports on the importance of this media have been discussed comprehensively $[10,11,12]$. The influx of these social media and networks necessitated the study on the preference of students in the use of WhatsApp and voice calls. Overall the study makes three important contributions: firstly, the familiarity of voice call and WhatsApp among polytechnic students in Ghana and its benefits in their 
broad spectrum of their academic live as well as their general daily communications. Over all 501 representing $84 \%$ of the students were familiar with the application. Its seeming benefits such as - the ability to create, share, adapt and reuse content engage in digital dialogue and collaborate, have peer-to-peer contact, social interaction with other users, its discoverability, and continuous accessibility have attracted greater number of students with the study revealing that $50 \%$ of the students use the platform, which confirms findings of Ofcom [4] that 58\% adults have been using the messenger.

Although the students were familiar with voice call, $67 \%$ of them use the service. However, some of their mobile phones were not compatible with WhatsApp application. In spite of the high percentage usage of voice call, the study cannot empirically confirm that this high usage indicate their preference, since some mobile phones are not compatible with WhatsApp. The study therefore concentrated on students whose phones were compatible with WhatsApp. The results indicated that 92\% (Figure 7) of the students prefer WhatsApp application to voice call; as a result WhatsApp was the major mode of communication (Figure 5). This reflected in their daily (Table 1) and situational usage (Table 2) of the application.

\subsection{Conclusions}

It can be established from the study that students are more familiar with voice call than WhatsApp but with those who use both applications, WhatsApp was more preferred to voice calls, with some reasons such as its convenience and easier usage, its effectiveness and reliability, and it saves money. WhatsApp is used by the students to inform about their locations, to coordinate meetings, issues related to coursework, private exchanges of information and arrange for club meetings online etc. Despite its preference, students are sceptical about their personal privacy and data protection. Voice call is still the major dominant choice for the students at certain formal situations especially where they need to be more expressive and effective in their communication as well as familiarity of the messenger by the other communicant.

\section{References}

[1] Underwood, J. (2009). The impact of digital technologies on learning. Retrieved from URL:http://www.slideshare.net/pburgess/ [March 5, 2014]
[2] Cristian, B. O., Răzvan D., \& Eugen R. N. (2011). Estimating the importance of social media in consumers' education and information using new techniques. Amfiteatru Economic, 13(5)

[3] Yeboah, J. and Ewur, G. D. (2014). The impact of WhatsApp messenger usage on students' performance in tertiary institutions in Ghana. Journal of Education and Practice, 5(6): 222-1735.

[4] Ofcom Communications Market Report (2012) URL:Http://www.ofcom.org.uk/cmruk [Accessed: March 20, 2014]

[5] Lenhart, A. and Ling, R. (2010). Teens and mobile phones. Pew Research Center's Internet \& American Life Project. URL:Http:www.pewinternet.org/Reports/2010/ Teen-andMobile-Phones.aspx. [Retrieved: May 15, 2104]

[6] Klutse, F. D. (2013) WhatsApp killing telecom industry? URL:http://business.myjoy

online.com/pages/news/201302/100896.php [Retrieved: May 15, 2104]

[7] Ling, R. and Baron, N. S (2007) Text Messaging and IM: Linguistic Comparison of American College Data. Department of Language and Foreign Study American University, Washington DC

[8] Melissa, J. P. (2013). With voice, WhatsApp is now much better than your phone's texting app. URL:http://www.citeworld.com/mobile/ [Accessed: March 8, 2014]

[9] Lenhart, A., Ling, R., Campbell, S., \& Purcell, K. (2010). Teens and mobile phones. Washington, D.C.: Pew Internet \& American Life Project. Retrieved from http://pewinternet.org/Reports/2010/Teens-and-MobilePhones.aspx [Accessed: April 10, 2014]

[10] Shyti, B. (2011). The use of Information and Communication Technologies from the Students' of Elbasan University A. Xhuvani", Elbasan, Albania. International Review of Management and Marketing, 1(1): 14-18

[11] Boyd, D.M. \& Ellison, N.B. (2008). "Social Network Sites: Definition, History, and Scholarship," J Compur- Mediat Comm. 2008 (13), 210-230. Boyd D (2007), 'Why youth (heart) social network sites: the role of networked publics in teenage social life'. In: Buckingham D ed. MacArthur Foundation Series on Digital Learning: Youth, Identity, and Digital Media Volume. Cambridge, MA : MIT Press

[12] Safran, C. (2010). Social media in education: Application scenarios supporting communities in technology- enhanced learning. $\mathrm{PhD}$ thesis submitted to The Institute for Information Systems and Computer Media, Graz University of Technology. 